\title{
Optimal Siting of Electric Vehicle Charging Stations Based on Voronoi Diagram and FAHP Method
}

\author{
Zheci Tang, Chunlin Guo, Pengxin Hou, Yubo Fan \\ State Key Laboratory of Alternate Electrical Power System with Renewable Energy Sources, \\ North China Electric Power University, Beijing, China \\ Email: tangzheci05@163.com
}

Received March, 2013

\begin{abstract}
The electric vehicle charging station should be allocated based on traffic density, geographical distribution and other factors, and Voronoi diagram is adopted to set the service area of charging station. In combination with the actual situation of site selection of electric vehicle charging station, the comprehensive benefits index system is established. There are numerous factors influencing the site selection, among which there are uncertainty and fuzziness. The comprehensive evaluation method based on the fuzzy analysis and Analytical Hierarchy Process (AHP) is used to evaluate the comprehensive benefits in the site selection of electric vehicle charging stations, with the consultation of experts. This paper contributes to the best selection of comprehensive benefits and provides the reference for the decision-making of building the electric vehicle charging station. Actual examples show that the method proposed is effective.
\end{abstract}

Keywords: Electric Vehicles; Charging Station; Voronoi Diagram; Fuzzy-AHP; Optimal Siting

\section{Introduction}

With the growing problem of global fossil energy crisis and environmental degradation, all countries turn their attention to the development and application of new energy currently so that exploration and research of largescale electric vehicles has become a hot spot. Meantime, Markets around the world have a greater demand for family cars with economic development and the improvement of people's income levels, which has certain positive significance in improving residents' travel modes and the development of the automobile industry, but also has a negative impact on energy security and environmental protection. Construction of electric vehicle charging station is a prerequisite for the popularity of electric vehicles while improving the efficiency of energy supply network is one of the necessary conditions for electric vehicles widely used $[1,2]$.

\section{Basic Description of the Voronoi Diagram}

The Voronoi diagram on the plane is the result of each vertex $\operatorname{Pi}(\mathrm{i}=1,2, \ldots, \mathrm{n})$ in the point set $\mathrm{P}$ expanding outward at the same speed until they meet each other. These outmost points form open area, each of the re-

* This work is supported by: National High Technology R\&D Program of China (863Program) (2012AA050804), Key Project of the National Research Program of China (2011BAG02B14), National High Technology R\&D Program of China (863 Program) (2011AA05A109). maining points forms a convex polygon. The Voronoi diagram plays an important role in solving a distance-related geometry object problem, and has been widely applied in many areas related to the geometric information [3], especially in geospatial facility location analysis.

Suppose that $P=\left\{P_{1}, P_{2}, \cdots P_{n}\right\}, 3<n<\infty$ is a point set in the Euclidean plane, these points are different from each other, that is to say

$$
P_{i} \neq P_{j}, i \neq j, i, j \in I_{n}\{1,2, \cdots, n\}, d\left(P_{i}, P_{j}\right)
$$

represents the Euclidean distance between $P_{i}$ and $P_{j}$ Suppose there is a point $\mathrm{x}$ on the plane, then area

$$
V_{(i)} \approx\left\{x \in E^{2} \mid d\left(x, p_{i}\right)<d\left(x, p_{j}\right), \quad j=1,2, \cdots, n, j \neq i\right\}
$$

is called Voronoi polygon, remembered as $\mathrm{V}(\mathrm{pi})$. V polygon of each point comes together to form $\mathrm{V}$ diagram of the closest point. Figure 1 shows $\mathrm{V}$ polygon generated by given points $P_{1}, P_{2}, \ldots, P_{9}$.

\section{Fuzzy-AHP Model}

The site selection of electric vehicle charging station is a complex multi-factor system and its content of the evaluation is multifaceted. A comprehensive evaluation about the main factors affecting the location and its indicators would be carried out in order to select the optimal program from many other site options. In the current evaluation methods, the fuzzy comprehensive evaluation 
method and the Analytic Hierarchy Process are often

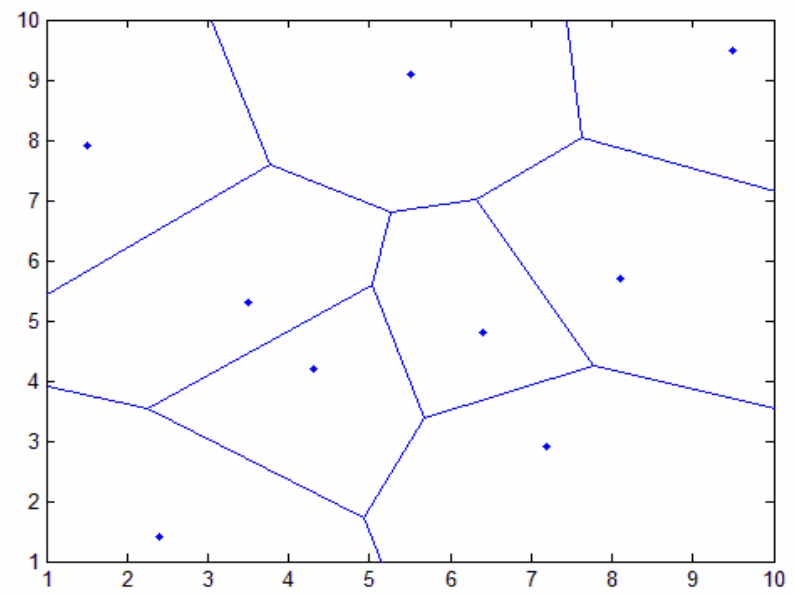

Figure 1. Voronoi diagram example.

used to evaluate the qualitative indicators. The fuzzy comprehensive evaluation method measures fuzzy differences with strict figures languages and utilizes membership function to divide its boundaries. But, establishment of the weight of fuzzy comprehensive evaluation often relies on the judgment of experts' subjective experience inevitably. Analytic Hierarchy Process (AHP) is a combination of qualitative and quantitative, expresses and processes the subjective judgment of persons with number forms, which would not only fully reflect the fuzziness of the evaluation index and the evaluation process, but also eliminate the one-sidedness of the subjective judgment so that the results of the evaluation could be more objective and credible. Therefore, this paper combines the advantages of these two methods, determines the weights of the sub-targets and indexes by AHP, evaluates the comprehensive benefits of the site selection of electric vehicle charging station by Fuzzy- AHP and provides the reference for the optimal decision-making of the site selection $[4,5]$.

Fuzzy-AHP is a comprehensive evaluation model that applies AHP and fuzzy comprehensive evaluation to the establishment of comprehensive evaluation model in fuzzy layer, gives play to the advantages of these two methods, takes full account of the various factors affecting the evaluation system, and combines the qualitative and quantitative analysis[6].

\subsection{Determine the Weights of Each Evaluation Index by AHP}

Analytic hierarchy process (AHP) was introduced by Professor T. L. Saaty, an American operations researcher, in the 1970. The basic principle of AHP is:

Through the analysis of factors and correlation of complicated system, make the problem methodical and hierarchical in order to objectively build a multi-level analysis structure model. Compare the various elements of each level pairwise, by introducing 1 9 ratio scaling method (Table 1) to construct the judgment matrix. Through calculating the biggest eigenvalues and corresponding eigenvectors of judgment matrix, getting importance orders of elements of all levels for a certain element, the weight vector is established. Finally, a comprehensive judgment is made. As follows are the main steps.

1) According to Table 1, construct comparison matrix pairwise, i.e., judgment matrix:

$$
A=\left(\alpha_{i j}\right)_{n \times n}(i, j=1,2, \cdots, n)
$$

where $\alpha_{i i}=1, \alpha_{i j}=1 / \alpha_{j i}$.

2) Multiply the elements of each row of the judgment matrix A, and find the nth root of the results respectively, i.e.

$$
\overline{W_{i}}=\left(\prod_{j=1}^{n} \alpha_{i j}\right)^{1 / n}
$$

3) Normalize $\overline{W_{i}}$ to achieve $W_{i}$.

$$
W_{i}=\bar{W}_{i} / \sum_{i=1}^{n} \bar{W}_{i}
$$

4) Calculate the maximum eigenvalues and their corresponding eigenvectors.

$$
\begin{gathered}
W=\left(W_{1}, W_{2}, \cdots, W_{n}\right) \\
\lambda_{\max }=\sum_{i=1}^{n}(A W)_{i} / n W_{i}
\end{gathered}
$$

5) Consistency check

a) Calculate the consistency index

$$
C I=\left(\lambda_{\max }-n\right) /(n-1)
$$

b) According to Table 2, find the average random consistency index RI corresponding to $C I$.

Table 1. 1 9 ratio scaling.

\begin{tabular}{cl}
\hline Criteria scale & \multicolumn{1}{c}{ Definition } \\
\hline 1 & $\mathrm{X}$ and $\mathrm{Y}$ are equally important \\
3 & $\mathrm{X}$ is a little important than $\mathrm{Y}$ \\
5 & $\mathrm{X}$ is obviously important than $\mathrm{Y}$ \\
7 & $\mathrm{X}$ is strongly important than $\mathrm{Y}$ \\
9 & $\mathrm{X}$ is absolutely important than $\mathrm{Y}$ \\
$2,4,6,8$ & Its important degree between the above \\
& two adjacent judgment value \\
\hline
\end{tabular}

Table 2. The average random consistency index $R I$ of the judgment matrix.

\begin{tabular}{cccccccccc}
\hline $\boldsymbol{n}$ & $\mathbf{1}$ & $\mathbf{2}$ & $\mathbf{3}$ & $\mathbf{4}$ & $\mathbf{5}$ & $\mathbf{6}$ & $\mathbf{7}$ & $\mathbf{8}$ & $\mathbf{9}$ \\
\hline$R I$ & 0 & 0 & 0.58 & 0.90 & 1.12 & 1.24 & 1.32 & 1.41 & 1.45 \\
\hline
\end{tabular}


c) Calculate consistency proportion $C R=C I / R I$

The judgment matrix A passes the consistency check When CR $<0.1$, otherwise, it is required to re-construct, until the consistency proportion meets the requirements.

\subsection{Main Steps of the Fuzzy-AHP Model}

1) The establishment of the factors set of comprehensive evaluation, $U=\left\{U_{1}, U_{2}, \cdots, U_{k}\right\}$, reflects the main indicators of the evaluation object (first grade indexes), which is also affected by the sub-indicators (secondary indexes).

$$
\begin{gathered}
U_{i}=\left\{u_{i 1}, u_{i 2}, \cdots, u_{i n_{j}}\right\}(i=1,2, \cdots, k) \\
n_{1}+n_{2}+\cdots+n_{k}=\sum_{i=1}^{k} n_{i}=n
\end{gathered}
$$

2) Determine the weight distribution set of secondary indexes according to the result of AHP.

$$
W_{i}=\left\{w_{i 1}, w_{i 2}, \cdots, w_{i n_{i}}\right\}(i=1,2, \cdots, k)
$$

3) Determine the weight distribution set of first grade indexes according to the result of AHP.

$$
A=\left\{A_{1}, A_{2}, \cdots, A_{k}\right\}
$$

4) In combination with the actual situation of site selection of electric vehicle charging station, select the evaluation set to form a judgment collection

$$
V=\left\{V_{1}, V_{2}, \cdots, V_{n}\right\} \text {. }
$$

In this model, $n=4$, the judgment collection is

$$
\left.V=\left\{V_{1}, V_{2}, \cdots, V_{n}\right\}=\text { \{better, good, general, poor }\right\}
$$

5) Evaluate secondary indexes by several experts' voting to reach evaluation matrix $R_{i}$.

$$
R_{i}=\left[\begin{array}{cccc}
r_{11} & r_{12} & r_{13} & r_{14} \\
r_{21} & r_{22} & r_{23} & r_{24} \\
\vdots & \vdots & \vdots & \vdots \\
r_{n_{i} 1} & r_{n_{i} 2} & r_{n_{i} 3} & r_{n_{i} 4}
\end{array}\right]
$$

6) Figure out the total evaluation matrix $B$.

a) Calculate the evaluation vector $B_{i}$ of every first grade index $U_{i}$.

$$
B_{i}=W_{i} \cdot R_{i}(i=1,2, \cdots, k)
$$

b) The total evaluation matrix $B$ is

$$
B=\left(B_{1}, B_{2}, \cdots, B_{k}\right)^{T}
$$

7) Obtain the total objective evaluation vector $C$.

$$
C=A \cdot B
$$

8) Figure out the comprehensive benefits of site selection of electric vehicle charging station after the total objective evaluation vector $C$ is ready, which depends on maximum membership degree law.

\section{Example of the Optimal Decision of the Site Selection of Electric Vehicle Charging Station}

\subsection{Use the Voronoi Diagram to Differentiate Areas}

Assuming a city as the planning area of electric vehicle charging station network, According to the city's traffic density distribution and regional distribution, several center points are selected. The Voronoi diagram is used to differentiate areas, in which a charging station is build, to finish the earlier work for charging station location. The center point is not necessarily the optimal charging station location. The optimal siting of charging station is optimized by using the Fuzzy-AHP model $[7,8]$.

\subsection{Establishment of Evaluation Index System for Electric Vehicle Charging Station Location}

Reviewing the related literature material and the principle of comprehensive evaluation index system, the comprehensive evaluation index system is established for electric vehicle charging station location, in consideration of traffic factors, economic factors, and social factors and influencing factors. Lane crossing number, road conditions and main roads are considered in the area of transportation; Total cost of construction investment, operation and maintenance, and cost of wear and tear are considered in. economic aspects. Social aspects include local government's opinions, construction conditions, technical conditions and resource distribution. Effects include environmental impact, power grid safety and people life, and so forth. An evaluation index system for electric vehicle charging station location is shown in Figure 2.

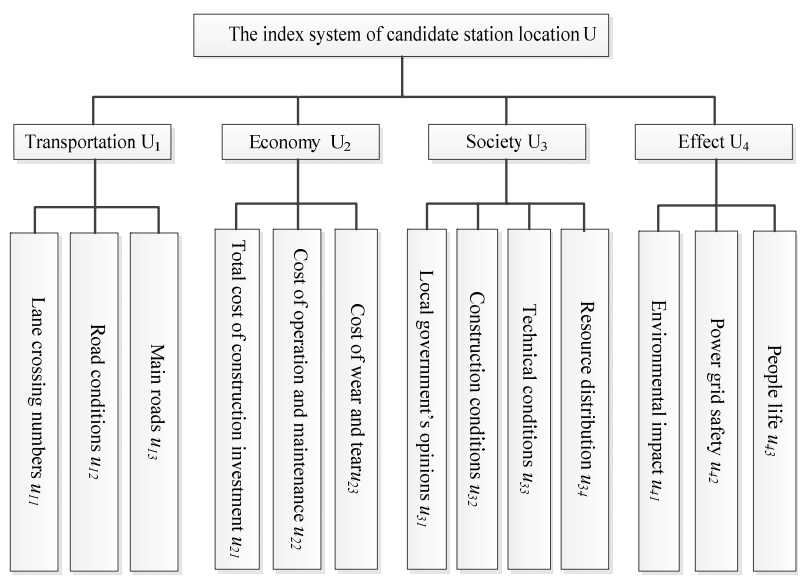

Figure 2. Comprehensive evaluation index system of the site selection of thermal power plant. 


\subsection{Determine the Weights of Each Evaluation Index by AHP}

\subsubsection{Establish Index Sets}

Four first grade indexes and thirteen secondary indexes in Figure $\mathbf{2}$ are established to evaluate the comprehensive benefits of the site selection of electric vehicle charging station. Then, comprehensive evaluation index set $U$ includes four first grade indexes, i.e.

$U=\left\{U_{1}, U_{2}, U_{3}, U_{4}\right\}$. The first grade indexes set is $\left\{U_{1}, U_{2}, U_{3}, U_{4}\right\}$, and thirteen secondary indexes are

$$
\begin{aligned}
& U_{1}=\left\{u_{11}, u_{12}, u_{13}\right\}, U_{2}=\left\{u_{21}, u_{22}, u_{23}\right\}, \\
& U_{3}=\left\{u_{31}, u_{32}, u_{33}, u_{34}\right\}, U_{4}=\left\{u_{41}, u_{42}, u_{43}\right\} .
\end{aligned}
$$

\subsubsection{Determine the Weights of Each Evaluation Index}

Reviewing a large number of the existing date, in consideration of the actual situation of electric vehicle charging station location, each level of judgment matrix based on Table 1 is established in order to calculate the weight of each index and have a consistency check [9].

Traffic factors are taken for example.

1) Construct judgment matrix of $U_{1}=\left\{u_{11}, u_{12}, u_{13}\right\}$

\begin{tabular}{cccc}
\hline $\mathrm{U}_{1}$ & $u_{11}$ & $u_{12}$ & $u_{13}$ \\
\hline$u_{11}$ & 1 & $1 / 3$ & $1 / 5$ \\
$u_{12}$ & 3 & 1 & $1 / 4$ \\
$u_{13}$ & 5 & 4 & 1 \\
\hline
\end{tabular}

2) Multiply the elements of each row of the judgment matrix, and find the 3th root of the results respectively.

So, $\overline{W_{11}}=0.41, \overline{W_{12}}=0.91, \overline{W_{13}}=2.71$.

3) Normalize $\overline{W_{1 i}}$ to achieve $W_{1 i}(i=1,2, \cdots, 5)$

$$
W_{11}=0.10, W_{12}=0.23, W_{13}=0.67
$$

4) Calculate the maximum eigenvalues and their corresponding eigenvectors. i.e.

$$
\begin{aligned}
& W_{1}=(0.10,0.23,0.67) \\
& \lambda_{\max }=\sum_{i=1}^{n}(A W)_{i} / n W_{i}=3.0863
\end{aligned}
$$

5) Consistency check

a) Calculate the consistency index

$$
C I=\left(\lambda_{\max }-n\right) /(n-1)=0.0432
$$

b) According Table 2, RI=0.58, $\mathrm{CR}=\mathrm{CI} / \mathrm{RI}=0.074<0.1$, the assignment of the judgment matrix constructed is reasonable. Similarly, the judgment matrixes about

$$
\begin{aligned}
& U_{2}=\left\{u_{21}, u_{22}, u_{23}\right\}, U_{3}=\left\{u_{31}, u_{32}, u_{33}, u_{34}\right\}, \\
& U_{4}=\left\{u_{41}, u_{42}, u_{43}\right\}, U=\left\{U_{1}, U_{2}, U_{3}, U_{4}\right\}
\end{aligned}
$$

as follows:

\begin{tabular}{cccc}
\hline $\mathrm{U}_{2}$ & $u_{21}$ & $u_{22}$ & $u_{23}$ \\
\hline$u_{21}$ & 1 & 5 & 5 \\
$u_{22}$ & $1 / 5$ & 1 & $1 / 2$ \\
$u_{23}$ & $1 / 5$ & 2 & 1 \\
\hline & & & \\
& & & \\
\hline $\mathrm{U}_{4}$ & $u_{41}$ & $u_{42}$ & $u_{43}$ \\
\hline$u_{41}$ & 1 & $1 / 5$ & $1 / 3$ \\
$u_{42}$ & 5 & 1 & 4 \\
$u_{43}$ & 3 & $1 / 4$ & 1 \\
\hline
\end{tabular}

\begin{tabular}{ccccc}
\hline $\mathrm{U}_{3}$ & $u_{31}$ & $u_{32}$ & $u_{33}$ & $u_{34}$ \\
\hline$u_{31}$ & 1 & $1 / 4$ & $1 / 4$ & $1 / 2$ \\
$u_{32}$ & 4 & 1 & 1 & 3 \\
$u_{33}$ & 4 & 1 & 1 & 4 \\
$u_{34}$ & 2 & $1 / 3$ & $1 / 4$ & 1 \\
\hline & & & & \\
\hline $\mathrm{U}$ & $\mathrm{U}_{1}$ & $\mathrm{U}_{2}$ & $\mathrm{U}_{3}$ & $\mathrm{U}_{4} \#$ \\
\hline $\mathrm{U}_{1}$ & 1 & $1 / 3$ & $1 / 2$ & $1 / 3$ \\
$\mathrm{U}_{2}$ & 3 & 1 & $1 / 2$ & $1 / 4$ \\
$\mathrm{U}_{3}$ & 2 & 2 & 1 & $1 / 2$ \\
$\mathrm{U}_{4}$ & 3 & 4 & 2 & 1 \\
\hline & & & &
\end{tabular}

Finally, the result is:

$$
\begin{aligned}
& W_{2}=(0.71,0.11,0.18) \\
& W_{3}=(0.08,0.38,0.41,0.13) \\
& W_{4}=(0.10,0.67,0.23) \\
& A=(0.11,0.17,0.25,0.47)
\end{aligned}
$$

\subsection{Construct a Fuzzy Evaluation Matrix}

Evaluate each index by ten experts' voting, the result is shown in Table 3.

According the result in Table 3, by calculating the membership degree of each index corresponding evaluation sets, the fuzzy evaluation matrix are:

$$
\begin{aligned}
& R_{1}=\left[\begin{array}{cccc}
0.2 & 0.4 & 0.4 & 0 \\
0.1 & 0.6 & 0.2 & 0.1 \\
0.4 & 0.4 & 0.2 & 0
\end{array}\right] R_{2}=\left[\begin{array}{llll}
0.3 & 0.4 & 0.2 & 0.1 \\
0.3 & 0.3 & 0.2 & 0.2 \\
0.4 & 0.2 & 0.3 & 0.1
\end{array}\right] \\
& R_{3}=\left[\begin{array}{cccc}
0.3 & 0.5 & 0.1 & 0.1 \\
0.2 & 0.5 & 0.2 & 0.1 \\
0.4 & 0.3 & 0.3 & 0 \\
0.1 & 0.4 & 0.3 & 0.2
\end{array}\right] R_{4}=\left[\begin{array}{llll}
0.1 & 0.3 & 0.4 & 0.2 \\
0.4 & 0.4 & 0.1 & 0.1 \\
0.2 & 0.3 & 0.3 & 0.2
\end{array}\right]
\end{aligned}
$$

The weight set $W_{1}=(0.10,0.23,0.67)$ is established by AHP, further, comprehensive evaluation vector about traffic is

$$
B_{1}=W_{1} \cdot R_{1}=(0.31,0.45,0.22,0.02)
$$

Similarly, according $W_{2}=(0.71,0.11,0.18)$, comprehensive evaluation vector about traffic is

$$
B_{2}=W_{2} \cdot R_{2}=(0.32,0.35,0.22,0.11)
$$

According $W_{3}=(0.08,0.38,0.41,0.13)$, comprehensive evaluation vector about traffic is

$$
B_{3}=W_{3} \cdot R_{3}=(0.28,0.41,0.25,0.07)
$$

According $W_{4}=(0.10,0.67,0.23)$, comprehensive evaluation vector about traffic is

$$
B_{4}=W_{4} \cdot R_{4}=(0.32,0.37,0.18,0.13)
$$

The general goal of the evaluation matrix is obtained from the B1, B2, B3 and B4.i.e. 
Table 3. Results of experts' voting to the index of the site selection of charging stations.

\begin{tabular}{|c|c|c|c|c|c|c|}
\hline \multirow{2}{*}{ First grade indexes } & \multirow{2}{*}{ Secondary indexes } & \multirow{2}{*}{ weight } & \multicolumn{4}{|c|}{ evaluation grade } \\
\hline & & & better & good & general & poor \\
\hline Transportation & Lane crossing numbers $u_{11}$ & 0.10 & 2 & 4 & 4 & 0 \\
\hline \multirow[t]{2}{*}{$\mathrm{U}_{1} 0.11$} & Road conditions $u_{12}$ & 0.23 & 1 & 6 & 2 & 1 \\
\hline & Main roads $u_{13}$ & 0.67 & 4 & 4 & 2 & 0 \\
\hline Economy & Total cost of construction investment $u_{21}$ & 0.71 & 3 & 4 & 2 & 1 \\
\hline \multirow[t]{2}{*}{$\mathrm{U}_{2} 0.17$} & Cost of operation and maintenance $u_{22}$ & 0.11 & 3 & 3 & 2 & 2 \\
\hline & Cost of wear and tear $u_{23}$ & 0.18 & 4 & 2 & 3 & 1 \\
\hline Society & Local government's opinions $u_{31}$ & 0.08 & 3 & 5 & 1 & 1 \\
\hline \multirow[t]{3}{*}{$\mathrm{U}_{3} 0.25$} & Construction conditions $u_{32}$ & 0.38 & 2 & 5 & 2 & 1 \\
\hline & Technical conditions $u_{33}$ & 0.41 & 4 & 3 & 3 & 0 \\
\hline & Resource distribution $u_{34}$ & 0.13 & 1 & 4 & 3 & 2 \\
\hline Effect & Environmental impact $u_{41}$ & 0.10 & 1 & 3 & 4 & 2 \\
\hline \multirow[t]{2}{*}{$\mathrm{U}_{4} 0.47$} & Power grid safety $u_{42}$ & 0.67 & 4 & 4 & 1 & 1 \\
\hline & People life $u_{43}$ & 0.23 & 2 & 3 & 3 & 2 \\
\hline
\end{tabular}

$$
B=\left(B_{1}, B_{2}, B_{3}, B_{4}\right)^{T}=\left[\begin{array}{llll}
0.31 & 0.45 & 0.22 & 0.02 \\
0.32 & 0.35 & 0.22 & 0.11 \\
0.28 & 0.41 & 0.25 & 0.07 \\
0.32 & 0.37 & 0.18 & 0.13
\end{array}\right]
$$

\subsection{The Comprehensive Benefit Evaluation of Electric Vehicle Charging Stations Location}

The general goal of the evaluation vector about electric vehicle charging stations location, i.e. $C=A \cdot B=(0.31$, $0.39,0.21,0.10$ ) is the result of the weight set of first grade evaluation indexes calculated by AHP $[10,11]$.

The comprehensive benefit of electric vehicle charging station location is better and the site is reasonable, which is based on the maximum membership degree law [12].

\section{Conclusions}

1) The Voronoi diagram is used to divide the zone, in which a charging station is build, to finish the earlier work for charging station location. The center point is not necessarily the optimal charging station location. The optimal siting of charging station is optimized by using the Fuzzy-AHP model.

2) The FAHP model combining AHP and fuzzy comprehensive evaluation, takes the advantages of the two approaches at the same time. Considering various factors of electric vehicle charging station location, the organic combination of the qualitative and quantitative analysis not only adequately reflect the fuzziness of evaluation index and evaluation process, but also try to eliminate one-sidedness of individual subjective judgment. There- fore, the evaluation results are more objective and credible.

\section{REFERENCES}

[1] F. Xu, G. Q. Yu, L. F. Gu, et al. Tentative analysis of layout of electrical vehicle charging stations," East China Electric Power, Vol. 37, No. 10, 2007, pp. 1678 -1682.

[2] F. Q. Zhou, Z. W. Lian, X. L. Wang, et al., "Discussion on Operation Mode to the Electric Vehicle Charging Station," Power System Protection and Control, Vol. 38, No. 21, 2010, pp. 63-67.

[3] J. H. Chen, D. Sheng, W. Li, et al., “A Model of Multi Objective Comprehensive Evaluation for Power Plant Projects," Proceedings of the CSEE, Vol. 22, No. 12, 2002, pp. 152-155.

[4] D. X. Niu, "The Gray Layer Analysis Method for Optimal siting of Thermal Power Plant,” Power System Technology, 1994, Vol. 18, No. 6, pp. 27-31.

[5] Y. F. Zhao, J. F. Chen, W. L. Guo, "The Analytic Process and its Application in Power Decision-making System," Relay, Vol. 33, No. 3, 2005, pp. 83-88.

[6] J. G. Kang, Z. L. Wei, D. M. Cheng, et al., "Research on Electric Vehicle Charging Mode and Charging Stations Construction,” Power Demand Side Management, Vol. 11, No. 5, 2009, pp. 64-66.

[7] C. Zhu, X. Ma and H. Gong, "Application of Fuzzy-AHP Model to the Decision-making of the Site Selection of Thermal Power Plant," Safety and Environmental Engineering, Vol. 17, No. 1, 2010, pp. 82-86.

[8] D. S. Wang, T. Liu and Y. H. Xie, "Substation Locating and Sizing Based on Hybrid Genetic Algorithm,” Automation of Electric Power Systems, 30, No. 6, 2006, pp. 30-34. 
[9] J. X. Yao, M. Wang and W. M. Luo, "Construction and Application of Charging Systems for Electric Mobiles," East China Electric Power, Vol. 36, No. 8, 2008, pp. 107-110.

[10] J. J. Xu, S. Y. Yang and J. Yuan, “A New Method of Selecting Location of Country's Transformer Substation Based on Fuzzy-AHP,” Electrical Engineering, Vol. 1, 2009, pp. 65-69.

[11] Z. Dong, M. G. Han, C. Q. Xu, et al., "Application of the Analytic Hierarchy Process in Buried Rebuilding of Ur- ban Electrical Network, ” Relay, 2006, Vol. 34, No. 22, pp. 64-68.

[12] R. R. Clarke, "Choosing an Integrated Resource Plan for Electric Utilities: An Analytic Hierarchy Approach," Proceedings of the Intersociety Energy Conversion Engineering Conference, Washington, USA: IEEE, 1996, pp. 1592-1597. 